\title{
PERANCANGAN SITUS WEBSITE SISTEM PEMASARAN PADA PT. RADJAWALI MENGGUNAKAN BAHASA PEMROGRAM PHP DAN DATABASE MYSQL
}

\author{
Eko Amri Jaya \\ Sistem Informasi, Sekolah Tinggi Teknologi Industri Padang \\ email:ekoamrijaya@sttind.ac.id.
}

\begin{abstract}
ABSTRAK
Pada saat ini teknologi informasi mengalami perkembangan yang sangat cepat, seiring dengan kebutuhan manusia yang juga terus bertambah. Teknologi memegang peranan yang sangat penting bagi kehidupan manusia. Teknologi internet merupakan salah satu bidang yang mengalami perkembangan sangat cepat. Telah banyak sektor yang menerapkan teknologi ini, salah satunya dalam bidang perdagangan. Lalu muncul perdagangan dengan internet sebagai sarana utama, yaitu e-commerce. Implementasi e-commerce dalam dunia bisnis salah satunya adalah dengan banyak bermunculan situs-situs penjualan secara online atau berbasis web. $E$ Commerce merupakan salah satu konsep baru yang bisa digambarkan sebagai proses jual beli barang atau jasa pada World Wide Web Internet. Dengan adanya web ini dapat memberikan dampak yang efisiensi dan efektifitas, serta dapat mengangkat produk atau citra dari PT. Radjawali.
\end{abstract}

Kata kunci : E-Commerce, Internet, uml, php, mysql

\section{PENDAHULUAN}

\subsection{Latar Belakang Masalah}

Pada saat ini teknologi informasi mengalami perkembangan yang sangat cepat, seiring dengan kebutuhan manusia yang juga terus bertambah. Teknologi memegang peranan yang sangat penting bagi kehidupan manusia. Zaman memang telah berubah begitu pula kita harus dapat mengikuti perkembangannya.

Teknologi internet merupakan salah satu bidang yang mengalami perkembangan sangat cepat. Telah banyak sektor yang menerapkan teknologi ini, salah satunya dalam bidang perdagangan. Lalu muncul perdagangan dengan internet sebagai sarana utama, yaitu e-commerce. Implementasi e-commerce dalam dunia bisnis salah satunya adalah dengan banyak bermunculan situs-situs penjualan secara online atau berbasis web.

E-Commerce merupakan salah satu konsep baru yang bisa digambarkan sebagai proses jual beli barang atau jasa pada World Wide Web Internet. E-Commerce kini semakin digemari oleh banyak orang karena keberadaan E-Commerce telah terbukti mempertinggi promosi produk dan layanan melalui kontak langsung, kaya informasi, dan interaksi dengan pelanggan.

Penggunaan web salah satunya adalah dalam pemberian informasi tentang Folding Gate yang tersedia dan cara pemesanan Folding gate untuk pelanggan pada PT. Radjawali. Selama ini, transaksi jual beli hanya dilakukan secara manual. Dengan adanya web ini dapat memberikan dampak yang efisiensi dan efektifitas, serta dapat mengangkat produk atau citra dari PT. Radjawali.

\section{METODE PENELITIAN}

\subsection{Jenis Penelitian}

Jenis penelitian yang penelitian lakukan adalah penelitian terapan. Hasil penelitian tersebut tidak perlu sebagai suatu penemuan baru, tetapi merupaan 
aplikasi baru yang bermanfaat bagi pengguna.

\subsection{Variabel Penelitian}

\section{Variabel penelitian adalah segala sesuatu yang akan menjadi objek pengamatan dalam penelitian. Sesuai permasalahan yang di teliti, maka variabel penelitian meliputi data-data pemasaran pada PT. Radjawali.}

\subsection{Langkah Metode Penelitian}

Untuk memperoleh data dan informasi dalam menyusun skripsi, maka diperlukan metode dalam pengumpulan data. Adapun metode pengumpulan data yang digunakan penulis dalam memperoleh data yaitu :

1. Pengumpulan data-data pemasaran. 2. Menyediakan software untuk membangun sebuah aplikasi pemasaran secaran online.

\subsection{Data Dan Sumber Data}

Data- data yang dibutuhkan dalam penelitian ini ada 2 yaitu : data primer dan

data

sekunder.

a. Data Primer adalah data yang didapat langsung dari wawancara dengan pemilik dan konsumen.

b. Data Sekunder Data sekunder diperoleh dari studi kepustakaan, bukubuku literatur

\section{HASIL DAN PEMBAHASAN}

\subsection{Analisis Sistem}

Analisis sistem informasi merupakan penguraian suatu system informasi yang utuh ke dalam bagian komponenkomponennya dengan maksud untuk mengidentifikasi dan mengevaluasi permasalahan-permasalahan,

kesempatan-kesempatan, hambatanhambatan yang terjadi, dan kebutuhankebutuhan yang diharapkan sehingga dapat diusulkan perbaikan untuk membuat sistem yang baru.
Langkah pertama dalam membuat sistem baru ini adalah mempelajari sistem yang sedang berjalan pada sebuah organisasi beserta dengan permasalahannya. Tujuannya adalah untuk mendapatkan gambaran secara jelas tentang bentuk permasalahan yang ada pada organisasi tersebut.

\subsubsection{Use Case Diagram}

Use case diagram berfungsi untuk mengambarkan kebutuhan fungsional dan menggambarkan kelakuan (behavior) sistem yang akan dibuat serta mendeskripsikan sebuah interaksi antara satu atau lebih aktor dengan sistem yang kan dibuat. Use case diagram pada sistem pemesanan produk dapat dilihat pada Gambar 3.1 berikut :

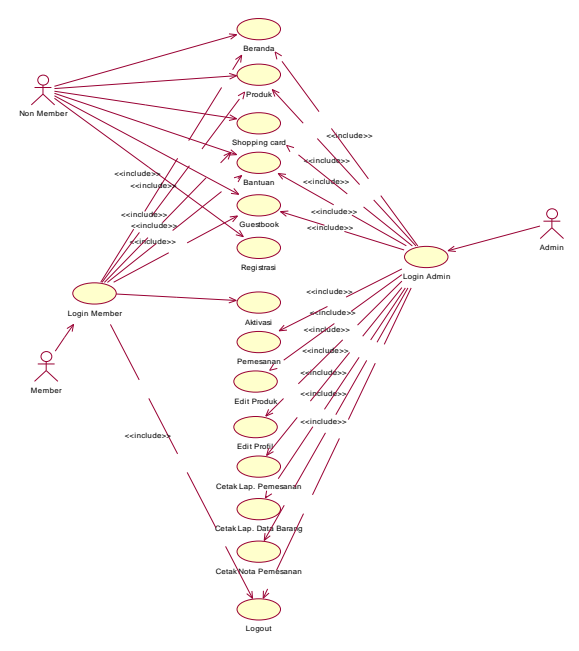

Gambar 1. Use Case Diagram

\subsubsection{Class Diagram}

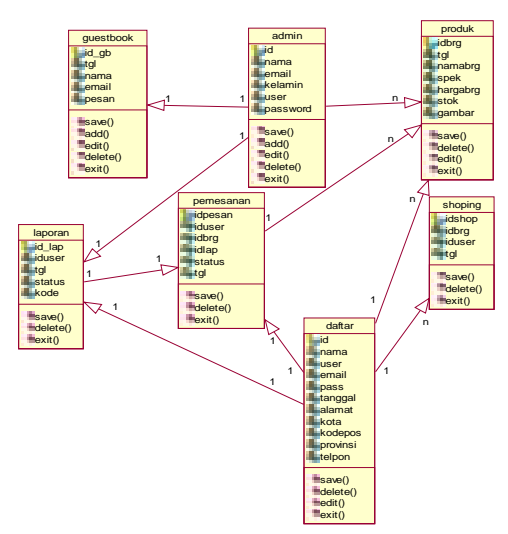

Gambar 2. Class Diagram Sistem

Pemesanan Produk 


\subsubsection{Activity Diagram}

\section{Activity Diagram Admin}

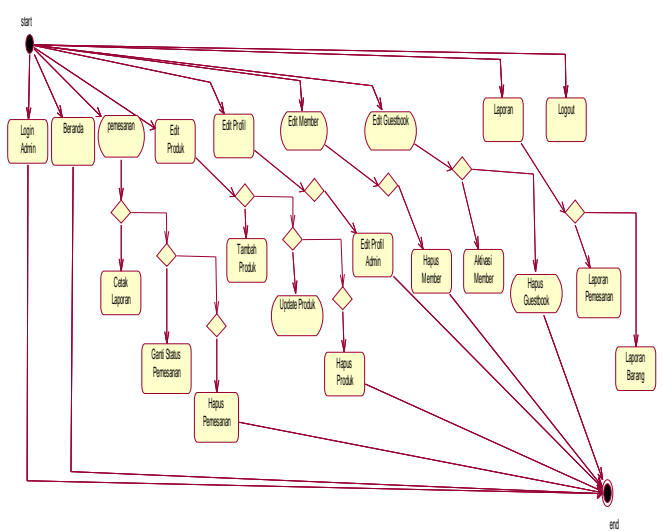

Gambar 3. Activity Diagram Admin

2. Activity Diagram Member

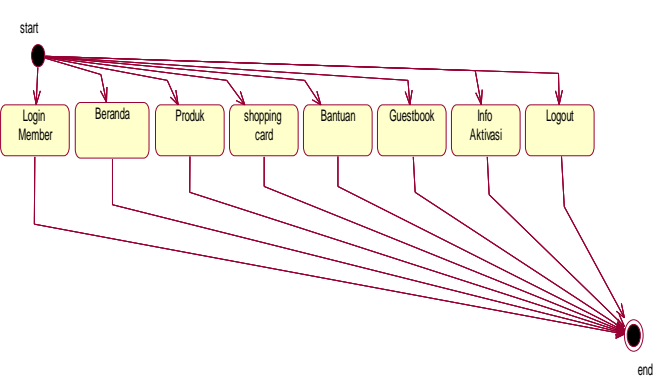

Gambar 4. Activity Diagram Member

\section{Activity Diagram NonMember}

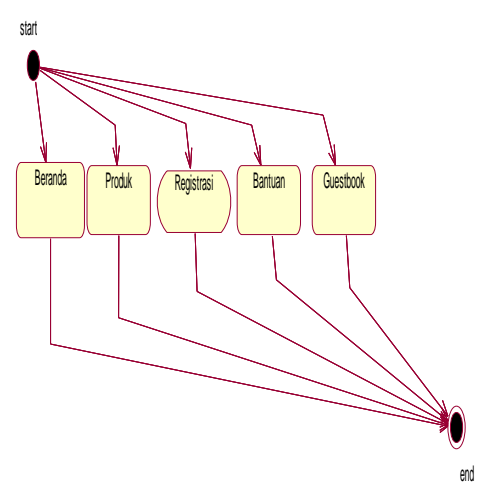

Gambar 5. Activity Diagram NonMember

\subsubsection{Sequence Diagram}

1. Sequence Diagram Admin Login

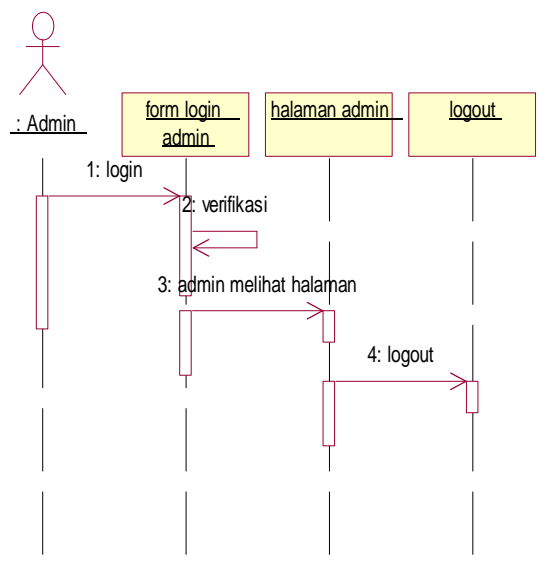

Gambar 6. Sequence Diagram Admin Login

\section{Sequence Diagram Admin Edit} Produk

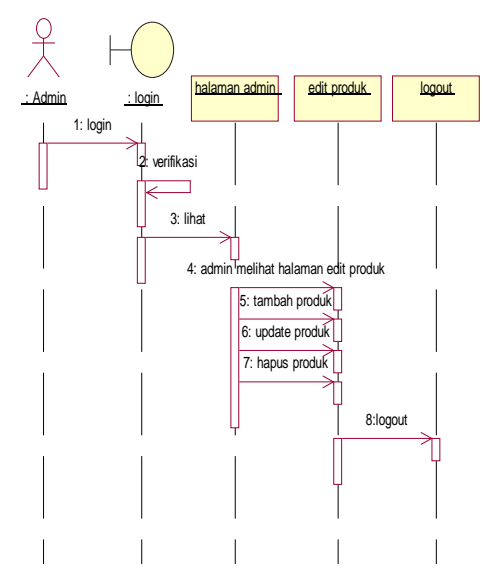

Gambar 7. Sequence Diagram Admin Edit Produk

3. Sequence Diagram Admin Melakukan Edit Member

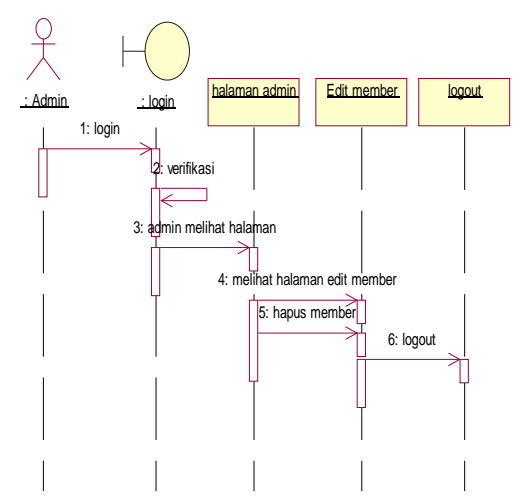

Gambar 8. Sequence Diagram Admin Melakukan Edit Member 
4. Sequence Diagram Admin Melakukan Kelola Pemesanan

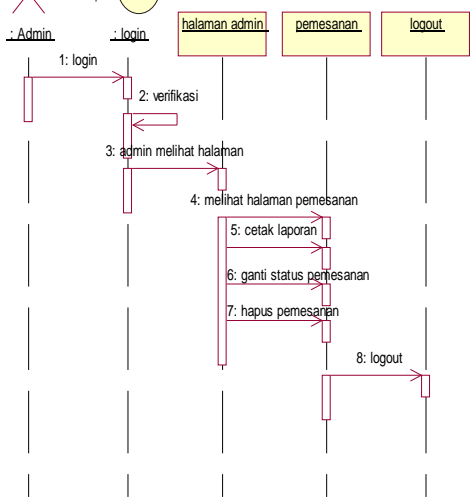

Gambar 9. Sequence Diagram Admin Melakukan Kelola Pemesanan

6. Sequence diagram Member Login

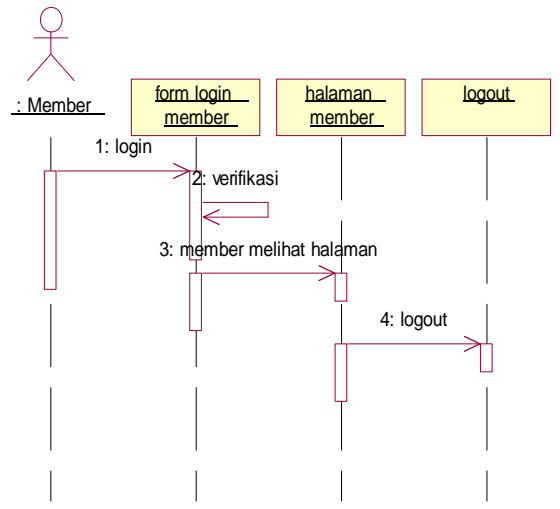

Gambar 10. Sequence Diagram Member Login

7. Sequence Diagram Member Melakukan Pemesanan

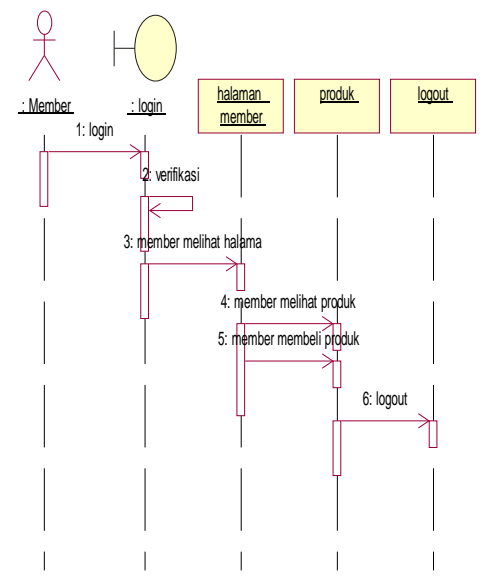

Gambar 11. Sequence Diagram Member Melakukan Pemesanan

\section{Sequence Diagram NonMember Melakukan Registrasi}

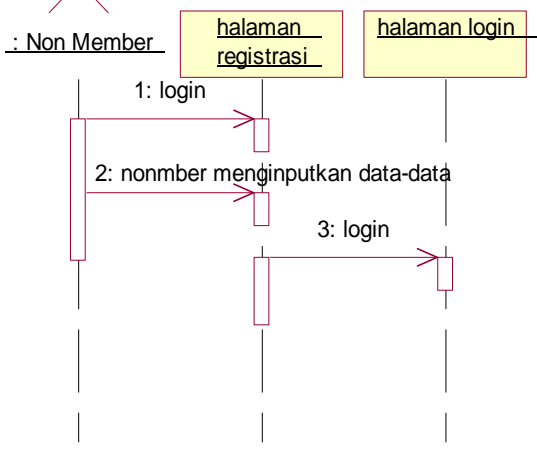

Gambar 12. Sequence Diagram

NonMember Melakukan Registrasi

\section{Sequence Diagram Kegiatan NonMember}

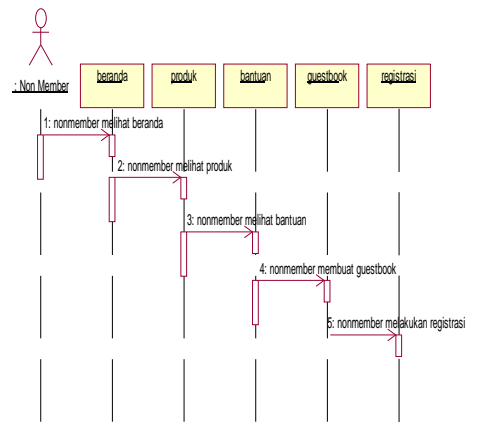

Gambar 13. Sequence Diagram Kegiatan NonMember

\subsection{Desain Terinci}

Didalam membuat desain secara detail, terlebih dahulu menetapkan rancangan output laporan-laporan yang diperlukan setelah itu baru ditentukan input-input yang dibutuhkan, kemudian kita mulai melakukan perencanaan file-file yang digunakan dalam pembuatan laporan tersebut.

\subsection{Desain Output}

Merupakan suatu model keluaran dari sistem informasi dalam bentuk laporan yang ditampilkan ke layar monitor maupun ke mesin cetak (printer). Berdasarkan rancangan UML diatas dan kebutuhan sistem yang ada, maka dirancang beberapa bentuk keluaran atau output yang akan diberikan kepada pimpinan dan user 
lainnya. Berikut adalah rancangan output dari sistem informasi pemesanan produk PT. Radjawali.

\subsection{Desain File}

Didalam disain file akan dibutuhkan suatu struktur data yang terdiri dari field-field serta item-item yang membutuhkan file tersebut. File adalah kumpulan dari record-record yang tersusun secara logis, file tersebut digunakan untuk mendapatkan informasi yang diinginkan.

\section{File Admin}

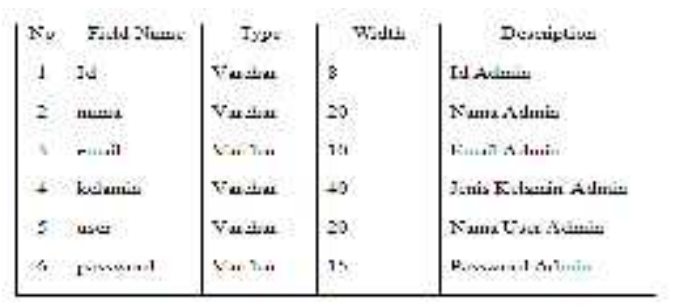

\section{File Daftar}

\begin{tabular}{|c|c|c|c|c|}
\hline 73 & $\Rightarrow$ th:m & $7 .+5$ & काजा ह & 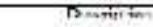 \\
\hline$T$ & स & There & & 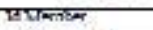 \\
\hline$=$ & $\mathrm{a}=\mathrm{s}$ & netax & so & 2thandeanser \\
\hline$=$ & - & vinten & $x$ & Nien:-1. \\
\hline - & लाखा & vwrts & . & Alumer $\mathrm{Tr} \times 1$ \\
\hline 4 & 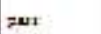 & vartax & 79 & Puirmoes membe: \\
\hline 6 & Eamal & vate & :० & ImBECPastedlez \\
\hline$\gamma$ & Learai & rent & 10 & Neare slestites \\
\hline *: & ata & vintion & $\bullet$ & Katum an \\
\hline ". & 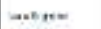 & vistor & 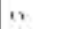 & 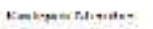 \\
\hline$*$ & 201200 & Vectie & $\therefore 0$ & Buinge Divate \\
\hline , & 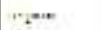 & waster & in & 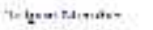 \\
\hline
\end{tabular}

\section{File Laporan}

\begin{tabular}{|c|c|c|c|c|}
\hline Vin & F.ald Kares & Thpo & Writh & Dacrivin \\
\hline$T$ & Colax & Interager & 4 & IdLayour \\
\hline 2 & ccuser & Varchar & 4 & IdUser \\
\hline 3 & s] & Volla & 30 & Tariggall Lupaut \\
\hline 1 & atre & Vexcher & 20 & Siatud Panbcion \\
\hline ; & inda & Vrrhser & 50 & Kintermethl: \\
\hline
\end{tabular}

\section{File Pemesanan}

\begin{tabular}{|c|c|c|c|c|}
\hline$\$$ & Fles Xant & Type & Whes & Fesçiva \\
\hline I & Exesx & Flegrer & 2 & Jo_șoch \\
\hline : & irme & Vereser & 4 & diviar \\
\hline$\vdots$ & ibls & Verritsr & $\vdots 0$ & J63 \\
\hline 4 & tis & Veriber & 8 & 1d:axn \\
\hline & sutas & Verrisr & 50 & Stra P are:ars, \\
\hline 6 & E. & Vercher & 30 & Trgai penasnon \\
\hline
\end{tabular}

\section{File Produk}

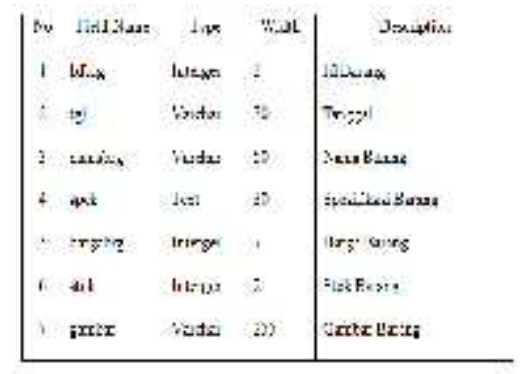

\section{File Shoping}

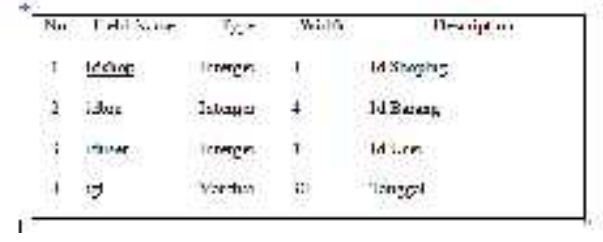

\section{TESTING DAN IMPLEMENTASI}

Dalam rancangan website penjualan alat kesehatan ini penulis menggunakan software pendukung yaitu XAMPP Control Panel

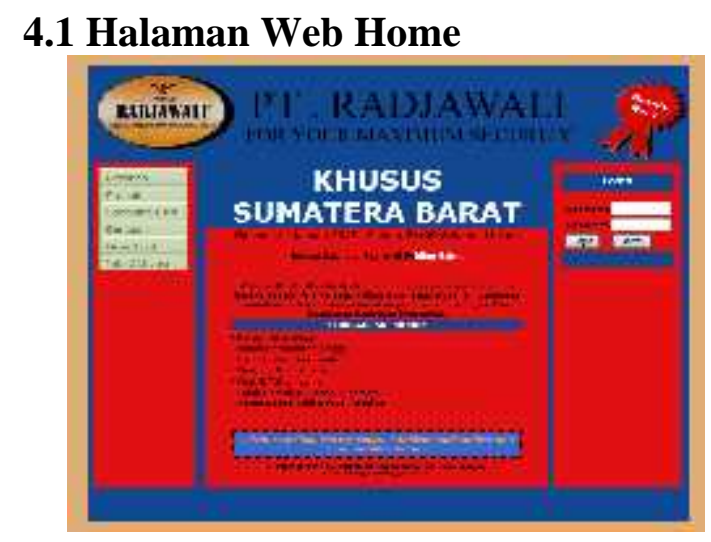

\subsection{Tampilan Halaman Guestbook}

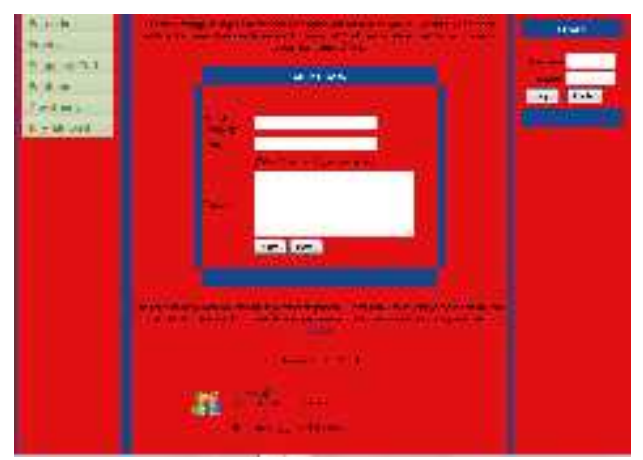




\subsection{Tampilan Halaman Bantuan}

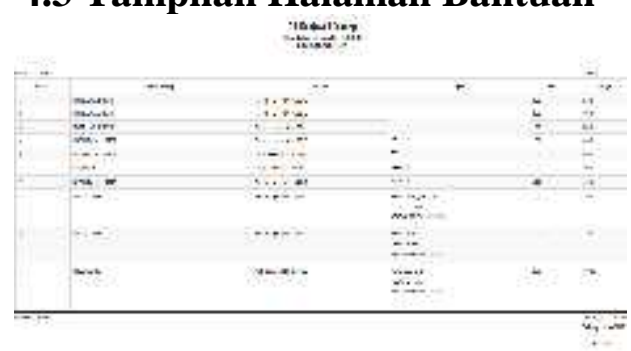

V. KESIMPULAN

Berdasarkan uraian-uraian dan rancangan sistem yang telah dijelaskan pada bab-bab sebelumnya, maka penulis mengambil kesimpulan.

1. Untuk mendapatkan informasi tentang produk yang. Konsumen dapat mengakses website yang telah di sediakan oleh PT. Radjawali melalui internet selama 24 jam. Hal ini tentunya akan memberikan kemudahan bagi konsumen.

2. Sistem yang dirancang ini akan mempermudah PT. Radjawali dalam menjual produk kepada konsumen.

3. Dengan adanya Database konsumen, pihak PT. Radjawali dapat menyimpan informasi data konsumen dengan baik dan pencarian data dengan cepat.

4. Hasil dari perancangan sistem yang baru ini, semoga dapat mengatasi kendala-kendala yang ada dan bermanfaat bagi PT. Radjawali.

\section{DAFTAR REFERENSI}

Deni Darmawan, Dr, S.Pd, M.Si \& Deden Hendra Permana. 2013. Desain dan Pemrograman Website. Bandung: PT Remaja Rosdakarya Offset.

Jogiyanto HM. 2009. Sistem Teknologi Informasi. Yogyakarta: Andi Offset.
Kadir, Abdul. 2010. Mudah Mempelajari Database MySQL, Ed. I. Yogyakarta.

Kadir, Abdul. 2014. Pengenalan Sistem Informasi Edisi Revisi, Ed. II. Yogyakarta.

Prasetio, Adhi. 2014. Buku Sakti Webmaster (PHP \& MySQL, HTML \& CSS, HTML5 \& CSS3, JavaScript). Jakarta.

Rosa A.S, \& M. Shalahuddin. 2013. Rekayasa Perangkat Lunak : Terstruktur dan Berorientasi Objek. Bandung: BI-Obsest. 